\title{
0 processo de formulação e monitoramento do planejamento estratégico de Tribunais de Contas sob a ótica da Nova Sociologia Institucional
}

\author{
Flávia de Araújo e Silva \\ Universidade Federal de Minas Gerais / Departamento de Ciências Contábeis \\ Belo Horizonte / MG - Brasil \\ Poueri do Carmo Mário \\ Universidade Federal de Minas Gerais / Departamento de Ciências Contábeis \\ Centro Universitário UNA / Programa de Mestrado Profissional em Administração \\ Belo Horizonte / MG - Brasil
}

\begin{abstract}
O objetivo desta pesquisa foi descrever o processo de adoção do planejamento estratégico nos Tribunais de Contas brasileiros, desde o planejamento até o monitoramento, sob a ótica da Nova Sociologia Institucional. A metodologia de pesquisa utilizou-se de survey e pesquisa documental analisando os casos de 23 Tribunais que responderam a questionário. Como resultados e contribuição da pesquisa, verificou-se que esse processo, por ainda ser recente para muitos Tribunais (em grande parte deles), está em fase de amadurecimento e nem todas as melhores práticas vêm sendo observadas, restando ainda algumas barreiras a serem superadas para colocar o sistema de planejamento e monitoramento operando efetivamente. Verificaram-se vários aspectos do isomorfismo no processo de formulação e na definição da metodologia de monitoramento, como o fato de a quase totalidade dessas organizações usar o balanced scorecard.
\end{abstract}

Palavras-chave: planejamento estratégico; monitoramento; Tribunais de Contas; institucionalismo.

El proceso de formulación y seguimiento de la planificación estratégica de los Tribunales de Cuentas desde la perspectiva de la Nueva Sociología Institucional

El objetivo de este estudio es describir el proceso de adopción de la planificación estratégica en los Tribunales de Cuentas brasileños, desde la planificación hasta la supervisión, bajo la óptica de la Nueva Sociología Institucional. La metodología de investigación utilizó una encuesta y la investigación documental, analizando los casos de veintitrés tribunales que han respondido a un cuestionario. Como resultado y la asistencia, se encontró que este proceso es todavía nuevo para muchos Tribunales (una

DOI: http://dx.doi.org/10.1590/0034-7612134757

(c) (1)

Artigo recebido em 12 maio 2014 e aceito em 30 jun. 2015. 
gran parte de ella), está en la misma etapa de maduración y no se ha observado mejores prácticas, a pesar de algunos obstáculos que todavía impiden a superar para poner el sistema de planificación y seguimiento operativo de manera efectiva. Hubo varios aspectos del isomorfismo en la formulación y definición de la metodología de seguimiento, por ejemplo, el hecho de que casi todas estas organizaciones utilizan el Cuadro de Mando Integral (BSC).

Palabras clave: planificación estratégica; seguimiento; tribunales de auditoría; institucionalismo.

The process of formulation and monitoring of strategic planning of Courts of Auditors from the perspective of New Institutional Sociology

The aim of this study was to describe the adoption process of the strategic planning in Brazilian Courts of Auditors, from planning to monitoring, under the view of the New Institutional Sociology. The research methodology was the survey and documentary research, analyzing the cases of twenty-three courts that responded to the questionnaire. As a result and contribution, it was found that this process — for being still new to many courts (in large part thereof) — is in the same ripening stage and not all best practices have been observed, although some remaining barriers have to be overcome to put the system planning and monitoring operating effectively. There were several aspects of the isomorphism in the formulation process and in the definition of the monitoring methodology, for example, the fact that almost all of these organizations use the Balanced Scorecard.

KEYWORDs: strategic planning; monitoring; Courts of Auditors; institutionalism.

\section{Introdução}

A introdução de ferramentas gerenciais no âmbito das organizações públicas, num contexto da busca por resultados e maior efetividade nas ações promovidas pelo governo, vem ocorrendo desde os anos 1980 em alguns países do mundo (Hood, 1995) e, no Brasil, de forma mais expressiva, a partir dos anos 1990. A administração pública passou a buscar alinhamento estratégico com foco em resultados para atender a demanda de cidadãos cada vez mais conscientes e exigentes por serviços de qualidade. Reformas de gestão pública afloraram nesse contexto (Bresser-Pereira e Grau, 2006).

Um dos programas de governo que se enquadra no rol de reformas na Administração Pública é o Programa de modernização do sistema de controle externo dos Estados, Distrito Federal e Municípios brasileiros (Promoex) - realizado no período de 2006 a maio de 2013. O objetivo do Programa, segundo o Ministério do Planejamento, Orçamento e Gestão (MPOG), é o fortalecimento institucional do sistema de controle externo para apoiar a implementação da Lei de Responsabilidade Fiscal, de forma que os Tribunais de Contas pudessem exercer suas competências de forma mais eficaz (Brasil, 2013). O Promoex tem foco em cinco áreas que apresentaram deficiência no diagnóstico preliminar realizado em 2002, entre elas, o planejamento e controle de gestão. Os Tribunais de Contas dos Estados, Distrito Federal e Municípios brasileiros são as entidades fiscalizadoras com jurisdição estadual e municipal, cujas competências constitucionais são a apreciação e o julgamento (conforme o caso) das contas prestadas pelos administradores públicos (Brasil, 2012). 
O processo de mudança pelo qual a administração pública vem passando nos últimos tempos repercutiu na forma com que as organizações estavam acostumadas a trabalhar: na maneira como passaram a gerenciar seus processos e as pessoas. Essas organizações passaram a buscar ferramentas gerenciais que pudessem aprimorar a gestão pública com foco em maior eficiência e efetividade, e uma das ferramentas que passou a ser utilizada foi o planejamento estratégico.

Considerando um contexto de implementação de uma nova ferramenta de gestão por órgãos da administração pública, especificamente nos órgãos de controle brasileiros, formulase o problema de pesquisa: como se deu o processo de adoção do planejamento estratégico pelos Tribunais de Contas brasileiros? O objetivo geral desta pesquisa é analisar o processo de adoção do planejamento estratégico nos Tribunais de Contas brasileiros, desde o planejamento até o monitoramento, sob a ótica da Teoria Institucional.

A justificativa para escolha do tema deve-se ao fato de que o planejamento estratégico e o monitoramento ainda são práticas de gestão em desenvolvimento no âmbito dos Tribunais de Contas (Silva e Mário, 2012; Ghisi, 2000). Todos os Tribunais de Contas participantes do Promoex estavam implementando o planejamento estratégico, que era uma das metas do Programa em relação às atividades planejadas para aprimoramento do controle gerencial. No âmbito dos Tribunais, trata-se de iniciativa bem recente, para grande parte desses órgãos de controle, pois muitos iniciaram a implementação após 2006. Por ter adoção relativamente recente, são necessárias pesquisas que busquem compreender os aspectos relacionados ao processo de planejamento e controle dentro das instituições, levantando as peculiaridades e dificuldades encontradas por organizações do setor público.

A relevância do tema que está sendo abordado nesta pesquisa é grande, especialmente no setor público em que os governos vêm sendo cada vez mais cobrados por eficiência e eficácia. Esta pesquisa, então, contribuirá tanto para o campo de estudo sobre institucionalização das práticas de gestão, como será útil para aquelas organizações públicas que estão iniciando os procedimentos de implementação de um sistema de planejamento estratégico, para que possam aprender com experiências de outros órgãos.

\section{Referencial teórico}

O referencial compreenderá três partes, iniciando-se pela Teoria Institucional, plataforma teórica que servirá de análise para o processo sob estudo, alinhando-se a revisão sintética dos temas cultura organizacional e planejamento estratégico e monitoramento. Como o objeto de pesquisa foi a análise da implantação do Planejamento Estratégico e o acompanhamento do mesmo, além de se efetuar a análise desse processo sob a ótica de uma teoria, é necessário resgatar aspectos importantes de Cultura e Comportamento Organizacional (visto tratar-se de entidades com regulamentação e procedimentos definidos legalmente), assim como de conceitos e definições operacionais sobre a ferramenta Planejamento Estratégico, as outras duas partes deste referencial. 
Considerando que o referencial aqui tratado vem de uma ampla literatura (quantidade e extensão temporal), adotaram-se como abordagem para se tratar o tema do item 2.1, Teoria Institucional, as indicações bibliométricas de Guarrido Filho (2008), cuja tese apresenta a quantidade de citações realizadas por autores do tema no período de 1993 a 2007, demonstrando a utilização imperativa dos denominados trabalhos clássicos, todos de origem estrangeira. Os artigos aqui utilizados têm sido os mais citados no mainstream de trabalhos sobre Teoria Institucional, mantendo-se como base para a leitura e análise de contextos, como o desta pesquisa. Autores como Meyer, DiMaggio, Powell e Scott são os mais citados segundo Guarrido Filho (2008), que identificou um quadro de citações, a seguir adaptado para este trabalho.

\section{Tabela 1}

Quantidade de citações de autores da NIS

\begin{tabular}{|lc|}
\hline Autor & Quantidade de citações \\
\hline Meyer & 278 \\
DiMaggio & 361 \\
Powell & 337 \\
Scott & 442 \\
Zucker & 151 \\
Tolbert & 88 \\
Selznick & 107 \\
\hline
\end{tabular}

Fonte: Adaptada de Guarrido Filho (2008:156).

\subsection{Teoria Institucional - Nova Sociologia Institucional}

O estudo da Teoria Institucional pode auxiliar na explicação dos fenômenos gerenciais a partir de padrões de comportamento, normas, crenças e procedimentos utilizados pelas instituições para ganhar legitimidade no ambiente em que operam, uma vez que essa teoria destaca a ideia de legitimação das práticas, ou seja, para que as organizações sejam percebidas como legítimas, devem se articular em torno de regras e crenças institucionalizadas (Dias Filho e Machado, 2004).

Existem três vertentes na Teoria Institucional que podem ser utilizadas na pesquisa sobre fenômenos gerenciais: a Nova Economia Institucional, a Nova Sociologia Institucional e a Velha Economia institucional. Nesta pesquisa, será utilizada como base para fundamentação teórica a vertente da Nova Sociologia Institucional, cujo foco está na relação entre as organizações e o ambiente no qual elas estão inseridas, apresentando uma interdependência social e cultural (Scott, 1987; Reis, 2008). 
Os estudos embasados na Nova Sociologia Institucional investigam processos de legitimação externa, as pressões que ocorrem de fora para dentro nas instituições, e como elas se adaptam a essas pressões. Como exemplo: adoção de instrumentos gerenciais formais (como o orçamento), para garantir legitimidade perante o usuário externo (acionistas e financiadores), ou adoção de uma nova norma contábil emitida por um organismo regulador (Ribeiro e Scapens, 2006).

Segundo Meyer e Rowan (1977), a vertente da Nova Sociologia Institucional utiliza um elemento alternativo para análise do processo de gerenciamento das organizações, especialmente nas atividades de controle e coordenação, que é a legitimidade de estruturas formais racionalizadas. Para esses autores, na sociedade moderna, as estruturas formais se desenvolveram em contextos muito institucionalizados, de forma que elas refletem os mitos dos ambientes institucionalizados em vez de apenas exigências técnicas de eficiência. Esse fenômeno é explicado pelo isomorfismo, que analisa como uma organização reflete uma realidade socialmente constituída. O isomorfismo é um elemento de grande importância no contexto da teoria institucional e é conceituado por DiMaggio e Powell (1983) como instrumento de mudança institucional que força uma unidade da população a assemelhar-se com outras unidades que pareçam estar nas mesmas condições em relação ao ambiente em que operam.

O isomorfismo é o resultado das pressões competitivas que forçam as organizações a se adaptarem como forma de sobrevivência no mercado (DiMaggio e Powell, 1983). Existem três mecanismos de influência que operam nas organizações de um mesmo ambiente:

a) Isomorfismo coercitivo: é aquele que se origina das influências políticas e das questões de legitimidade; a organização é submetida a pressões externas de diversos stakeholders (outras organizações, sociedade, governo etc.);

b) Isomorfismo mimético: ocorre quando uma organização imita práticas de outras como forma de ter resposta às incertezas ambientais;

c) Isomorfismo normativo: se associa à profissionalização, ou seja, envolve o compartilhamento de um conjunto de normas e métodos de trabalho pelos membros de um segmento; são estabelecidos padrões por uma classe profissional.

As organizações tendem a se parecer com as outras porque estão envolvidas numa competição, não apenas por recursos e consumidores, mas também por poder político e legitimidade institucional, oportunidades sociais e econômicas. Com a prática do isomorfismo, as organizações inseridas em ambientes institucionais legitimam-se e obtêm recursos, de forma que as organizações adaptam-se aos ambientes não direcionadas por questões de eficiência, mas por uma busca de legitimação (DiMaggio e Powell, 1983).

Para Selznick (1972), a institucionalização é um processo: algo que acontece a uma organização com o passar do tempo, mostrando sua história particular, as pessoas que nela trabalham, os grupos que engloba com os interesses diferenciados que criaram e a maneira como vai se adaptando ao seu ambiente. 
Para Tolbert e Zucker (1999), as fases do processo de institucionalização passam por: (i) habitualização: desenvolvimento de comportamentos padronizados e novos arranjos estruturais para a solução de problemas organizacionais específicos, associando estes a estímulos particulares; é uma fase de pré-institucionalização; (ii) objetificação: desenvolvimento de significados gerais socialmente compartilhados relacionados a esses comportamentos; fase necessária para a transposição de ações para contextos além do ponto de origem; (iii) sedimentação: processo em que as ações adquirem a qualidade de exterioridade, ou seja, as tipificações são vivenciadas como se possuíssem realidade própria.

Tolbert e Zucker (1999:208) apontam que a total institucionalização da estrutura depende dos efeitos conjuntos de "uma relativa baixa resistência de grupos de oposição; promoção e apoio cultural continuado por grupos de defensores; correlação positiva com resultados desejados".

\subsubsection{Estudos recentes na administração pública sob a abordagem institucional}

Serão apresentados, de forma breve, os achados de dois estudos brasileiros conduzidos no setor público nos últimos três anos, na área de contabilidade gerencial e avaliação de políticas públicas, e que utilizaram da abordagem institucional. Essas pesquisas servem para verificar como essa teoria pode auxiliar no campo de estudos da área gerencial pública.

Borges (2012) pesquisou a implementação de práticas gerenciais no Governo do Estado de Minas Gerais, objetivando identificar a existência, a compreensão e a utilização dos relatórios contábeis gerenciais pelos gestores do nível médio do governo, em um contexto de gestão para resultados e de implementação das novas normas brasileiras de contabilidade do setor público. O trabalho descreveu o ambiente institucional na visão dos gestores entrevistados e apresentou como as mudanças institucionais acontecem segundo a Nova Sociologia Institucional. Como conclusão, o autor apontou que, para os gestores entrevistados, o foco dos instrumentos é a produção de informação para tomada de decisão dos gerentes de alto escalão do governo, em detrimento da disponibilização de informações para auxílio aos gerentes médios. Em relação ao uso do orçamento, por exemplo, o autor destacou que "A contabilidade, em toda a sua amplitude de aplicações, cumpre um papel secundário como um instrumento gerencial para os gerentes médios, representando mais um mecanismo de adequação às regras formais estabelecidas" (Borges, 2012:117). Apesar de existirem organizações dentro do governo que institucionalizaram uma valorização do modelo de gestão de forma efetiva, elas acabam sofrendo interferência dos órgãos centrais que atuam de outra forma.

Bechelaine e colaboradores (2013) pesquisaram a influência dos processos de institucionalização na utilização das avaliações de políticas públicas do governo do estado de Minas Gerais, examinando em que medida essas avaliações foram concebidas e implementadas com intuito de favorecer a utilização dos seus resultados. A estratégia de pesquisa utilizada foi o estudo de caso, com realização de entrevistas com os gerentes de projetos estruturadores avaliados pelo processo de Avaliação Executiva de Projetos. Os autores concluíram que a forma 
de construção do processo de avaliações não permitiu a real institucionalização do procedimento. Um dos fatores, por exemplo, foi que o processo foi desenhado (tanto na metodologia de avaliação como na escolha dos projetos a serem avaliados) sem a participação dos atores envolvidos, ou seja, foi top down. Foi identificada também uma lacuna na questão de adoção de incentivos para utilização das oportunidades de melhorias apresentadas em cada projeto avaliado. Os autores também apontam que a avaliação executiva ainda se encontra descolada tanto do ciclo de planejamento e orçamento estadual, quanto da lógica de monitoramento dos projetos estruturadores. Bechelaine e colaboradores (2013) acrescentam que a ausência de uma institucionalização da entidade que proporcionou a avaliação também poderia enfraquecer a utilização de seus resultados, além da ausência de uma formalização do processo de avaliação executiva por meio de um ato normativo.

Apresentados alguns aspectos relevantes da Teoria Institucional, que apoiaram a análise do processo de adoção do planejamento estratégico pelos Tribunais de Contas, a próxima sessão apresentará, de forma breve, alguns pontos relevantes da cultura organizacional e sua relação com a resistência à mudança, que serão necessários para uma melhor compreensão das características do processo sob análise nesta pesquisa.

\subsection{Cultura e mudança organizacional}

A cultura organizacional pode ser definida como um sistema de significados partilhados mantidos pelos membros de uma organização, de forma a distingui-la de outras organizações. Esse sistema de significados é um conjunto de características-chave que a organização valoriza (Robbins, 1999).

Para Pereira e colaboradores (2010), a cultura organizacional permeia toda a organização influenciando a maneira de executar as atividades por meio das características humanas presentes nas organizações.

Entretanto, existem aspectos disfuncionais da cultura para a eficácia de uma organização, como a barreira à mudança: quando o ambiente está passando por uma mudança, a cultura da organização pode não ser mais apropriada e pode tornar difícil as respostas às mudanças no ambiente (Robbins, 1999).

As mudanças ocorrem nas organizações com uma velocidade cada vez maior do que fora observado em tempos passados por diversas pressões do ambiente no qual estão inseridas: pressões tecnológicas, força de trabalho, concorrência, choques econômicos, tendências sociais, política mundial são alguns exemplos. Entretanto, os estudos de comportamento organizacional apontam que as organizações e seus membros resistem à mudança. Para Lewin (1948), a resistência à mudança é o resultado da tendência de um grupo de indivíduos a se opor às forças sociais que possam conduzir o sistema a novos patamares de equilíbrio.

No âmbito da administração pública, alguns autores apontam a resistência à mudança como traço marcante e que dificulta a implementação de novas práticas na organização (Guimarães, Pordeus e Campos, 2010; Pereira, 2006; Giacobbo, 1997). 


\subsection{0 processo de planejamento estratégico e monitoramento}

O processo de controle gerencial, que envolve o ciclo iniciado com a formulação do planejamento estratégico, passa pela implementação e vai até o controle e análise de resultados; objetiva assegurar que as atividades sejam desempenhadas de acordo com o planejado.

Para Bryson (1988), o planejamento estratégico é desenhado para ajudar organizações públicas e não orientadas ao lucro a responderem de forma efetiva às novas situações. É um esforço disciplinado para produzir decisões fundamentadas para moldar a natureza e a direção das atividades de uma organização, dentro de certos limites legais. Na construção do planejamento estratégico são realizadas discussões entre gerentes e tomadores de decisão para definir o que é realmente importante para a organização.

Nesta pesquisa, o planejamento estratégico será entendido como o processo que inicia com a formulação de estratégias elaboradas com vistas ao alcance de uma visão de futuro, passa pela implementação das iniciativas e deve ser continuamente monitorado de modo a possibilitar a verificação do alcance das metas em relação ao que foi planejado, finalizando com o feedback dos resultados aos stakeholders.

Mintzberg (2006) discorre sobre o sistema de planejamento e sobre o desdobramento das estratégias formuladas: o sistema começa com o planejamento estratégico, em que a organização avalia suas forças e fraquezas considerando as tendências do ambiente no qual está inserida e, depois, formula as estratégias integradas que pretende seguir no futuro. Essas estratégias são depois desdobradas em programas e projetos.

A adoção de Planejamento Estratégico no setor público é mais recente que na esfera privada, mas nos últimos anos seu uso vem crescendo gradualmente (Pereira, 2006). A implementação dessa metodologia de planejamento, com definição e monitoramento de metas, desencadeia uma grande mudança na cultura organizacional, especialmente no setor público em que a condição de estabilidade dos servidores e os planos de remuneração não costumam gerar motivação por desempenhos extraordinários (Silva e Gonçalves, 2011). Bryson (1988) aponta que as organizações devem contar com o apoio de um patrocinador com posição de poder para legitimar o processo de implementação do planejamento estratégico.

Formulado o planejamento estratégico de uma organização, passa-se à fase de implementação que, segundo Poister (2010), deve envolver o trabalho em conjunto de todas as alavancas gerenciais num esforço concentrado para implementar as iniciativas estratégicas, avançando nas questões inicialmente planejadas, por meio do uso de planos de ação, orçamentos, desenvolvimento e treinamento da força de trabalho etc., além da habilidade da organização para influenciar outros atores da rede na qual opera. O autor também aponta que as organizações devem designar um responsável principal para implementação das estratégias (gerentes ou unidades) para possibilitar a supervisão da implementação de estratégias que envolvem diversas unidades.

Outra fase do ciclo de planejamento é o monitoramento da execução das ações planejadas. O monitoramento pode ser entendido como o acompanhamento contínuo e cotidiano da execução dos programas e das políticas pelos gestores ou agentes externos à administração 
pública em comparação com os objetivos e metas planejadas (Vaitsman, Rodrigues e PaesSousa, 2006; Guimarães, Pordeus e Campos, 2010).

Outro conceito bastante utilizado no monitoramento é desempenho, que pode ser conceituado, segundo Catelli (2001), como as atividades realizadas pela organização que modificam seu estado, buscando o desenvolvimento da organização. No âmbito das entidades fiscalizadoras superiores, a Organização Internacional de Entidades Fiscalizadoras Superiores (Intosai) (2013) aponta que a essência das definições sobre desempenho se resume ao cumprimento de determinada tarefa medida contra padrões definidos.

Cavalluzzo e Ittner (2004) pesquisaram sobre fatores determinantes para alcançar sucesso na implementação de um sistema de mensuração de desempenho em entidades governamentais, destacando: (i) um bom sistema de informações para subsidiar a mensuração de forma tempestiva e acurada; para Catelli (2001), a informação gerencial precisa estar sistematizada para auxiliar no processo de tomada de decisão; sistemas informatizados de gestão são bastante utilizados nas organizações para armazenar a base de dados gerenciais; (ii) escolha de métricas adequadas que possibilitem mensuração correta dos resultados alcançados, posição também defendida por Simons, Dávila e Kaplan (2000); (iii) autoridade que os gerentes devem possuir para tomar decisões baseadas nos indicadores de desempenho; (iv) comprometimento da alta administração para com o processo de implementação e uso das informações sobre resultados; (v) treinamento adequado de todos os participantes do processo para que entendam e aceitem a mudança implementada.

Vaitsman, Rodrigues e Paes-Sousa (2006) apontam que as ações de monitoramento abarcam as seguintes atividades: (i) definição do conjunto mínimo de indicadores que devem ser monitorados por programa ou ação; (ii) definição do conjunto mínimo de dados que devem ser coletados em cada programa ou ação; (iii) acompanhamento sistemático da execução física e financeira dos programas e ações; (iv) construção e implantação de sistemas de informações dos programas e ações; (v) coleta ou recebimento sistemático dos dados referentes aos programas e ações; (vi) supervisão in loco dos programas e ações executados; e (vii) produção e análise de indicadores referentes aos programas e ações.

Verifica-se que a existência de indicadores é parte importante do processo de monitoramento, fato que também é defendido por Ghisi (2000), que define indicador de desempenho como um número que mede um aspecto do desempenho, com a finalidade de comparar essa medida com metas previamente estabelecidas. Um indicador é um valor quantitativo que pode ser escalonado e usado como base de comparação, entre organizações ou entre períodos (Simons, Dávila e Kaplan, 2000).

Entre os modelos de planejamento e monitoramento utilizados no setor público, destacam-se o Balanced Scorecard (BSC) - metodologia de gestão estratégica desenvolvida por Kaplan e Norton em princípios da década de 1990 para o monitoramento do desempenho das estratégias implantadas (Kaplan e Norton, 1992; Berry et al., 2009; Cruz, Matias, e Frezatti, 2010) - e o Gerenciamento pelas Diretrizes, cuja filosofia, de origem japonesa, está pautada na concepção de que os resultados são conseguidos pela atuação criativa e dedicada das pessoas, focalizando o esforço de todos. 


\section{Procedimentos metodológicos}

Tendo em vista o objetivo geral estabelecido para esta pesquisa de analisar o processo de implementação do planejamento estratégico, desde o planejamento até o monitoramento, adotado pelos Tribunais de Contas brasileiros, desenvolveu-se uma pesquisa descritiva, segundo delineamento de Triviños (2007), uma vez que o foco é descrever os fatos e os fenômenos de uma dada realidade para uma melhor compreensão de como esse processo se desenvolve na esfera pública e gerar análises. Para esse fim, uma pesquisa documental e um levantamento por meio de questionário, instrumento principal para a análise, foram realizados.

A população é constituída pelos Tribunais de Contas dos estados e municípios brasileiros. A justificativa para escolha da população de estudo deve-se ao fato de que, sendo os Tribunais de Contas brasileiros os órgãos que auxiliam o Poder Legislativo no controle externo da gestão pública (Brasil, 2012), essas instituições já deveriam adotar práticas de monitoramento e avaliação, uma vez que elas realizam, entre outras atividades, auditorias de performance, verificando o alcance de resultados dos programas de governo de seus entes jurisdicionados.

Inicialmente, realizou-se pesquisa documental aos planos estratégicos dessas instituições. Os documentos pesquisados nas páginas institucionais eletrônicas foram os planejamentos estratégicos de cada TC. A pesquisa foi realizada no período entre julho e agosto de 2012. Foram utilizados os campos de busca em cada uma das páginas (portais eletrônicos), procurando pelas palavras-chave: "planejamento estratégico" ou "plano estratégico".

$\mathrm{O}$ intuito desta pesquisa documental foi de conhecer a estrutura de um plano estratégico sob a ótica e contexto de um TC, servindo de subsídio para a elaboração posteriormente do próprio questionário da pesquisa realizada.

Existe no Brasil um universo de 33 Tribunais de Contas estaduais e municipais. Foram obtidas respostas de 23 Tribunais, correspondendo a $70 \%$ do universo (uma parcela significativa de Tribunais no contexto brasileiro), ao questionário aplicado em novembro de 2012. Os termos "respondentes" ou "Tribunais" designam os servidores representantes das áreas de Planejamento, que, de forma geral, são os gestores responsáveis pelas unidades de Planejamento e que possuem conhecimento do processo sob análise, uma vez que acompanharam o processo de planejamento estratégico desde sua concepção, sendo, portanto, os mais indicados para opinar acerca do desenvolvimento do planejamento estratégico na instituição. Esses representantes das unidades de Planejamento também são os responsáveis, na maior parte dos Tribunais, pelo monitoramento do Projeto Promoex.

Os 23 Tribunais que responderam ao questionário estão sediados em cada uma das cinco regiões geográficas do país, variando bastante em porte, tempo de existência, perfil da administração, número de entidades jurisdicionadas sob fiscalização etc. Desse modo, os servidores que responderam à pesquisa afirmam ser difícil a comparação entre os Tribunais, devido às peculiaridades de cada um. Os Tribunais de Contas brasileiros participantes da amostra têm, em média, cerca de 55 anos de existência.

Conforme informado no próprio formulário do questionário, não foram identificados os Tribunais respondentes e cada um recebeu um número na apresentação dos resultados. A 
pesquisa iniciou-se com o levantamento das características do processo de gestão estratégica nos Tribunais de Contas: foi aplicado um questionário em todas essas instituições contemplando itens acerca da formulação estratégica e sobre o monitoramento da execução do plano estratégico.

O questionário acerca dos procedimentos do ciclo de planejamento estratégico dos Tribunais foi estruturado em duas partes: uma sobre formulação estratégica e outra sobre monitoramento, de forma a abranger parte significativa do processo de controle gerencial. O instrumento é composto de 35 itens, distribuídos em duas dimensões: (i) levantamento dos procedimentos adotados no processo de planejamento estratégico - composta por uma questão aberta, dois itens dicotômicos e 15 itens de múltipla escolha, em que se pode escolher mais de uma opção de resposta; e (ii) levantamento da percepção dos respondentes quanto aos aspectos qualitativos do processo - composta por 17 itens com escala Likert de cinco pontos (as alternativas de respostas vão de "Concordo Totalmente" a "Discordo Totalmente").

A primeira parte do questionário, sobre formulação estratégica, foi determinada a partir do questionário desenvolvido por Meirelles (2003). A segunda parte do questionário utilizou como base os estudos de Corrêa e Hourneaux Jr. (2007) e de Talbot, Daunton e Morgan (2001). Corrêa e Hourneaux Jr. (2007) elaboraram um questionário sobre o sistema de avaliação de desempenho organizacional, aplicado a organizações do setor químico. Talbot, Daunton e Morgan (2001) pesquisaram as práticas de mensuração de desempenho em oito países (Austrália, Canadá, Dinamarca, Finlândia, Holanda, Nova Zelândia, Suécia e Estados Unidos) considerados avançados em questão de mensuração de desempenho governamental.

Em suma, pode-se estruturar o questionário em dois grandes grupos, um que envolve a perspectiva de Formulação e Implementação e outro que abrange o Monitoramento e a Avaliação, conforme a tabela 2 .

Tabela 2

Estrutura do questionário e suas perspectivas

\begin{tabular}{|lc|}
\hline Perspectivas & Itens do questionário \\
\hline I. Formulação e Implementação do PE & 1 e 2 \\
Duração do processo de PE no órgão & 3 e 4 \\
Condução do processo de formulação & 5 e 6 \\
Procedimentos relacionados ao desdobramento e revisão do PE & 7 e 9,11 \\
Responsabilização dos atores do PE/envolvimento dos servidores & 8 \\
Relacionamento do Promoex com o processo de PE & 10 \\
Implementação do PE e mudança organizacional & 12 \\
II. Monitoramento e Avaliação do PE & 13 \\
Responsabilização pela condução do processo do PE & 14 a 17 \\
Metodologia para o PE & Continua \\
\hline
\end{tabular}




\begin{tabular}{|lc|}
\hline Perspectivas & Itens do questionário \\
\hline Accountability dos resultados & 18 e 19 \\
Incentivos para alcance de metas & 20 a 23 \\
Uso de sistema informatizado & 25 \\
Normatização do processo e controle de qualidade & 24 e 26,27 \\
Percepção sobre o envolvimento da alta administração & 28 \\
Percepção sobre o estágio em que se encontra o processo no órgão & $29,30,31,32,33$ e 35 \\
Percepção sobre a cultura organizacional e resistência & 30 e 34 \\
\hline
\end{tabular}

Fonte: Elaborada pelos autores.

O questionário teve sua validade testada junto a especialistas no tema, profissionais que atuam no âmbito de TC em área de Planejamento e Gestão, como forma de verificar se o instrumento aparentemente media aquilo que pretendia. Apesar de esse teste não ser suficiente para se concluir se a medida é de fato válida, é necessário realizá-lo antes de se avaliar os outros critérios de validade (Martins, 2006).

O questionário foi aplicado durante a II Oficina de Gestão Estratégica e Gerenciamento de Projetos realizada em Brasília (DF) em novembro de 2012, contando com a participação de representantes de 25 TC. A escolha pela aplicação do questionário de forma presencial se deu pelo fato de que um dos pesquisadores teve a oportunidade de esclarecer as dúvidas dos respondentes quanto às questões, além de conseguir um maior índice de retorno. Em pesquisas anteriores aplicadas por meio eletrônico, houve baixo índice de retorno. Dessa forma, os questionários enviados por e-mail foram destinados àqueles representantes de Tribunais que não compareceram ao evento.

\section{Resultados}

\subsection{Conteúdo dos planos estratégicos}

Nesse tópico será apresentado o resultado da pesquisa documental realizada nos planos estratégicos dos Tribunais de Contas para verificar o conteúdo dos mesmos. Essa descrição se faz importante para que se possa compreender o que está abrangido na concepção de planejamento estratégico para a amostra pesquisada. Verifica-se que, de acordo com revisão de literatura realizada, um planejamento estratégico geralmente é composto por concepção estratégica (definição da missão, visão e valores), análises dos cenários interno e externo no intuito de levantar potenciais problemas e oportunidades, assim como forças e fraquezas (SWOT), além da definição de objetivos, projetos/ações, metas e indicadores. Destaca-se que, dos 23 respondentes, apenas três não disponibilizam o plano vigente na internet.

Verifica-se que todos os planos apresentam um histórico sobre o planejamento estratégico na instituição, a missão, visão e valores, o mapa estratégico com os objetivos. Onze 
Tribunais não apresentam o diagnóstico dos cenários interno e externo. Dezessete Tribunais apresentam a metodologia utilizada para formulação estratégica, informando desde como foram conduzidas as reuniões de formulação estratégica até o modelo de monitoramento da execução. Alguns dos planos apresentam um framework do sistema/modelo de planejamento e monitoramento na parte da metodologia. Tal resultado também foi apresentado em pesquisa desenvolvida em 2011 com os Tribunais (Silva e Mário, 2012). Cinco Tribunais exibem o ato normativo que aprovou o plano estratégico na parte introdutória do documento - depreende-se que esse ato pode conferir credibilidade à informação apresentada.

Apenas cinco Tribunais não apresentam os indicadores de desempenho e, dos que apresentam, 13 explicam a forma de medição do indicador. As metas somente são apresentadas por sete Tribunais. As iniciativas/ações estratégicas são apresentadas por 14 Tribunais e os projetos por dois. Uma matriz de correlação entre iniciativas e objetivos estratégicos é apresentada por três Tribunais e um glossário com as definições dos termos utilizados é apresentado por três Tribunais.

Foi realizada uma pesquisa por objetivos estratégicos comuns aos Tribunais: 13 Tribunais definiram o "desenvolvimento/aprimoramento de um sistema de planejamento/gestão com foco em resultados" como um dos objetivos. Além desse, 14 Tribunais apresentaram os objetivos estratégicos "contribuir para a melhoria do desempenho/aprimoramento da gestão pública"; "estimular o controle social" e "fortalecer relacionamento com outros órgãos de controle/estabelecer parcerias". Outros objetivos comuns bastante encontrados foram: "conferir maior celeridade à tramitação dos processos/reduzir tempo de tramitação"; "intensificar o uso de tecnologia da informação"; "ampliar a transparência das ações/da gestão pública”. Em menor proporção aparece o objetivo "impulsionar a auditoria operacional/contribuir para a efetividade das políticas públicas".

Verifica-se também que esses objetivos estratégicos estão diretamente relacionados com os objetivos do Programa Promoex. Os planos estratégicos dessas instituições geralmente apresentam indicadores de desempenho, relacionados aos objetivos estratégicos, com predominância dos qualitativos, como: índice de satisfação da sociedade, índice de satisfação dos servidores, tempo médio de tramitação de processos, índice de conhecimento do Tribunal pela sociedade. Esses indicadores estão diretamente ligados aos objetivos ora apresentados. Há também indicadores relacionados ao sistema de monitoramento, como índice de alcance de metas e índice de implementação das ações planejadas. Dez Tribunais apresentam indicador relacionado à redução do estoque de processos, indicador que se relaciona ao objetivo estratégico de redução do estoque processual. Esse objetivo remete ao fato apresentado por Ribeiro (2002) de que a estrutura híbrida adotada pelos Tribunais, com funções de controladoria além das funções de um Tribunal de Contas, leva a problemas de tempestividade na condução dos processos.

Cabe destacar que os indicadores de desempenho mais importantes para avaliação de desempenho de Tribunais de Contas, segundo a percepção do Corpo Deliberativo dessas instituições, em pesquisa realizada no ano de 2007 pelo Instituto Rui Barbosa, são "tempo médio 
de tramitação de processos", "número de processos julgados/total de processos" e "quantidade de auditorias in loco realizadas/total de unidades" (IRB, 2014).

A existência de objetivos estratégicos e indicadores comuns aos Tribunais pode ser relacionada ao fato de que a grande maioria dessas organizações utilizou o plano de outro Tribunal como referência (questão do isomorfismo tratada anteriormente), assim como também se relaciona ao fato de os Tribunais possuírem cenários internos e externos muito semelhantes, apesar da peculiaridade de cada organização.

Interessante destacar que apenas três Tribunais apresentam indicador de "custo $\times$ benefício" das ações de controle externo ou recursos economizados com as ações de auditoria, enquanto esse é o principal indicador apresentado pelas entidades fiscalizadoras superiores do Reino Unido (National Audit Office-NAO) e Estados Unidos (U.S. Governement Audit Office-GAO) - quantificação de recursos economizados em relação à quantidade de recursos gastos pela instituição - de acordo com consulta feita nas páginas eletrônicas destes organismos (NAO, 2014; US GAO, 2014).

\subsection{Análise do processo de planejamento e monitoramento}

Para uma melhor compreensão dos resultados que serão expostos a seguir, cabe destacar que o cenário inicial (uma fase "pré-planejamento estratégico") das instituições analisadas é aquele apresentado pelo diagnóstico realizado em 2002 pela FIA/USP, antecedente ao Promoex, que apontou a falta de planejamento e controle gerencial no cenário dos Tribunais, de forma geral. Portanto, um dos objetivos do Promoex era fortalecer a capacidade institucional dos Tribunais por meio de planejamento estratégico e da modernização das suas estruturas organizacionais para melhoria da efetividade de sua gestão. Existem, então, três fases importantes para se analisar o contexto dos Tribunais: uma fase pré-Promoex, outra fase de implementação das ações previstas no Programa e a fase pós-Promoex, que está em curso.

Constata-se que o processo de planejamento estratégico é relativamente novo para cerca de metade dessas instituições, uma vez que 48\% dos respondentes instituíram seu primeiro plano a partir do ano de 2007. Em 2012, a maioria dos TC respondentes estava implementando o segundo ciclo de planejamento de longo prazo.

Como o processo de implantação do planejamento estratégico nos Tribunais era algo novo, entende-se que, por desconhecerem as práticas de gestão, os Tribunais necessitaram buscar o conhecimento para implementação dos novos procedimentos, o que se deu por meio de contratação de consultoria externa ou por meio de visitas técnicas em outros órgãos que já haviam iniciado o processo para servirem de referência.

Há evidências de que a questão do isomorfismo, conforme abordado por DiMaggio e Powell (1983), está presente no contexto dos Tribunais quando se verifica que quase todos os respondentes apontaram que o TC utilizou como referência o plano estratégico de outros Tribunais de Contas para formulação do seu próprio plano. O plano do TCU, por exemplo, foi citado por 12 representantes e o do TCE-RN por quatro, além de outras instituições que 
também foram mencionadas. Nesse ponto, remete-se ao isomorfismo mimético, pois, por se tratar de adoção de uma nova prática de gestão em que os participantes não têm muito conhecimento prévio sobre o assunto, pode haver incerteza quanto ao novo procedimento que está sendo desenvolvido, de modo que as instituições iniciantes no tema tendem a se moldar àquelas organizações reconhecidas como referência.

Outro ponto que cabe destacar foi a estratégia de atuação em rede dessas organizações que, por meio do Grupo de Planejamento Organizacional/Promoex, compartilharam a metodologia de elaboração e desdobramento do plano estratégico em diversas oficinas realizadas durante o período de 2009 a 2012, sem custo para os Tribunais estaduais e municipais, e sendo o TCU um dos multiplicadores do conhecimento entre os Tribunais (Silva, Martins e Ckagnazaroff, 2013). Essa forma de atuação também reforça a questão do isomorfismo mimético, pois, conforme apontam DiMaggio e Powell (1983), quanto maior for o grau de incerteza entre meios e fins, maior a probabilidade de a organização querer se assemelhar às organizações reconhecidas como bem-sucedidas.

Outro indício do processo de isomorfismo é o fato de que grande parte dos respondentes (15 TC) afirmou que o TC contratou consultoria externa para elaboração do primeiro planejamento estratégico. Um dos respondentes que afirmou não ter contratado consultoria para formulação do plano comentou que houve contratação para auxiliar no processo de desdobramento dos objetivos estratégicos, o que reflete a posição de Machado-da-Silva e Vizeu (2007) de que os escritórios de consultoria são agentes estratégicos que atuam no processo de estruturação da estratégia como prática organizacional. Na opinião de alguns representantes dos TC, a consultoria proporciona, além de conhecimento especializado sobre a temática, um olhar diferenciado (externo) e isento da organização, podendo evidenciar algumas falhas que talvez não fossem facilmente ditas pelos atores envolvidos no processo.

Os fatos apontados servem para entender por que a quase totalidade dos Tribunais da amostra utiliza como metodologia para monitoramento do planejamento estratégico o Balanced Scorecard (BSC): essas organizações se embasaram em metodologias utilizadas por outros órgãos públicos ou por empresas de consultoria. Apenas um Tribunal informou utilizar a metodologia do Gerenciamento pelas Diretrizes (GPD) e dois Tribunais utilizam as duas metodologias citadas de forma híbrida (BSC com GPD).

A fase de formulação estratégica, segundo a percepção dos respondentes, foi realizada de forma participativa, uma vez que todos afirmaram que foram ouvidas sugestões dos diversos setores da instituição na elaboração do plano estratégico. Nessa fase, costumam ser designados responsáveis formais pelo alcance de metas, ações ou objetivos estratégicos na maioria dessas organizações.

Os Tribunais criaram unidades específicas em suas estruturas organizacionais para coordenarem as ações do planejamento estratégico. Em 19 Tribunais existe uma Unidade de Planejamento que é responsável pelo monitoramento da execução do planejamento estratégico. Para quatro Tribunais existe um Comitê de Planejamento que executa ou auxilia nessa função. Adicionalmente, foi verificado que a existência de uma unidade de planejamento, regularmente instituída, com atribuições específicas, com estrutura física e de pessoal própria, 
é um dos critérios de avaliação dentro dos parâmetros de qualidade e agilidade do controle externo, definidos pelo Regulamento da Associação dos Membros dos Tribunais de Contas do Brasil (Atricon) nํㅜ 01/2013.

Pode-se depreender que houve um processo de mudança (ou tentativa de mudança, em alguns casos) iniciado com a adoção das novas ferramentas de gestão nas instituições estudadas: na opinião de 15 respondentes, a implementação do planejamento estratégico representou uma mudança inovadora nas práticas de gestão em relação ao que vinha sendo praticado até então. Um dos respondentes afirmou que a mudança só veio a acontecer após adoção da metodologia GPD no ano de 2012, apesar de o plano estratégico ter sido implementado em 2009.

A mudança organizacional dispara o processo de institucionalização, conforme Tolbert e Zucker (1999). No TCE-MT, por exemplo, foram encontrados trechos (tanto no plano estratégico como no livro que relata a experiência da organização) que relatam a ocorrência de uma transformação da administração burocrática para a administração gerencial ocorrida nesse órgão (Rodrigues Neto, 2009).

O processo de mudança organizacional, entretanto, poderia ter sido mais bem conduzido junto aos colaboradores, uma vez que apenas 35\% dos respondentes são de opinião que "a maioria dos servidores consegue relacionar o trabalho desenvolvido com o alcance dos resultados do plano"; $43 \%$ discordam ou discordam totalmente com o fato e $22 \%$ são indiferentes. Infere-se que nem todos os servidores desses Tribunais conseguem entender o processo de mudança que está sendo implementado em sua organização, segundo a opinião dos participantes da pesquisa. Um dos respondentes ponderou que os servidores estavam conseguindo fazer tal relacionamento, pois estava sendo feito o desdobramento de metas até o nível individual, com uso da metodologia GPD. Outro respondente afirmou que boa parte dos servidores não consegue fazer tal relação; apenas os envolvidos nas ações estratégicas. Um terceiro respondente afirmou que o pessoal de nível gerencial consegue fazer tal relacionamento, mas não todos os demais servidores.

Esse processo de mudança organizacional nos Tribunais teve como fator impulsionador o Programa Promoex: 83\% dos respondentes concordaram totalmente ou concordaram com a afirmação. Antes do início do Programa, em 2006, 11 dos 23 TC respondentes haviam implementado o primeiro ciclo de planejamento estratégico. Um dos respondentes afirmou que o Tribunal já possuía um plano antes do Promoex, mas, com o início do Programa, houve um impulso no planejamento.

Uma das metas do Promoex era que 100\% dos Tribunais implementassem ou revisassem o planejamento estratégico até o final do Programa, o que implica que a adoção da referida ferramenta de gestão não era optativa e sim mandatória para os Tribunais que aderiram ao Promoex (quase a totalidade deles), uma vez que essas instituições foram monitoradas durante a execução do Programa e, caso não tivessem iniciado alguns dos procedimentos estipulados como metas, teriam seus repasses de recursos financeiros interrompidos. Portanto, pode-se verificar aspectos do isomorfismo coercitivo de DiMaggio e Powell (1983) uma vez que não se deu opção para os Tribunais vinculados ao Promoex entre implementar ou não a 
ferramenta planejamento estratégico. Considerando ainda que o Promoex iniciou em 2006 e que, a partir de 2007, 48\% dos Tribunais implementaram o primeiro planejamento estratégico, fica evidente a força que o Programa teve para que grande parte dessas organizações adotasse a ferramenta.

Quanto aos procedimentos adotados no ciclo de planejamento, verifica-se que quase todos os Tribunais da amostra efetuam a revisão do plano estratégico de longo prazo anualmente (ou bianualmente em dois casos). Esses planos de longo prazo são desdobrados, na maioria dos Tribunais, em ciclos menores, com uso de planos anuais (ou bianuais), planos de ação ou projetos.

Quanto às práticas de monitoramento, verifica-se que os Tribunais vêm efetuando medição de prazos, projetos, ações e metas; poucos Tribunais monitoram, ainda, indicadores qualitativos e financeiros. A periodicidade dessa medição é variável, predominando a mensal. Também são realizadas reuniões de avaliação de resultados na maior parte dos Tribunais da amostra, com participação de todo o grupo de responsáveis e, em alguns casos, da alta administração. Essas reuniões ocorrem semestralmente (em alguns casos, mensalmente ou trimestralmente). Destaca-se que a aferição periódica de metas também é um dos critérios de avaliação dentro dos parâmetros de qualidade e agilidade do controle externo, definidos pelo Regulamento Atricon no 01/2013, mas apenas 10 Tribunais entre os 23 respondentes estão efetuando as medições das metas.

Os procedimentos adotados no planejamento e monitoramento estão normatizados em grande parte dos Tribunais da amostra. Alguns dos respondentes são de opinião que a publicação de um ato normativo, no qual estarão definidos as obrigações de cada uma das partes envolvidas no processo e os prazos para realização das tarefas, é um fator que corrobora para a implementação dos procedimentos, visto que a norma tem um peso sobre os envolvidos na instituição ao ditar as regras a serem seguidas. Isso reflete aspectos da burocracia de Weber (1994).

A fase de implementação e monitoramento do planejamento estratégico, por ser uma prática de gestão relativamente recente nas organizações estudadas, ainda encontra dificuldade para sua realização, de acordo com os relatos redigidos na survey. Conforme mencionado por um dos respondentes, o primeiro plano deles foi apenas um documento que ficou por implementar; apenas no segundo ciclo de planejamento o monitoramento passou a ser realizado. Outro respondente afirmou que o plano nunca foi implantado efetivamente e um terceiro afirmou que os primeiros dois planos foram apenas uma declaração, uma carta de intenções que nunca saíram do papel; apenas no terceiro plano houve uma implementação de fato. Esse relato vai ao encontro do que Machado-da-Silva e Vizeu (2007) chamaram de adoção cerimonial de práticas formais de estratégia, pois há apenas uma aparência de que existe planejamento estratégico; entretanto, ele não sai do papel.

Há que se destacar um ponto que mostra um esforço dos Tribunais para se modernizarem e para melhorar o gerenciamento e monitoramento do plano estratégico, que foi a implementação de um sistema informatizado de gestão do planejamento estratégico naqueles Tribunais que ainda não possuíam uma ferramenta para tal finalidade (quase a totalidade das 
instituições pesquisadas está implementando o sistema). Os Tribunais acreditam que o sistema informatizado poderá auxiliar muito no aprimoramento do processo de monitoramento (Silva e Mário, 2012).

Cabe destacar que quase todas as organizações pesquisadas informaram não dispor de procedimentos para garantir a qualidade da informação prestada pelos setores sobre resultados alcançados. Esse fato vai contra os preceitos de Talbot, Daunton e Morgan (2001) de que as organizações devem instituir procedimentos para atestar a confiabilidade das informações prestadas, ou seja, se elas refletem, de fato, o desempenho alcançado. Entretanto, alguns Tribunais estão buscando certificação ou avaliação externa de seus procedimentos: dois Tribunais são certificados pela ISO 9001 e dois participam do Programa de avaliação Gespública. Um dos respondentes que ainda não participa do Programa informou que tal adesão é uma meta para 2013. Nesse ponto, destaca-se a importância de se haver mecanismos para aferir a qualidade da informação, conforme pontuam Talbot, Daouton e Morgan (2001), de modo que a informação proporcionada seja confiável e válida para ser aceitável por todos os interessados. Quando as instituições são avaliadas por organismos externos, essa verificação da qualidade da informação que é produzida é levada em conta.

No processo de monitoramento, os respondentes apontaram que um dos fatores de dificuldades (mencionados pela quase totalidade dos Tribunais) foi a definição e mensuração dos indicadores de desempenho. Um dos respondentes reforçou comentando que a dificuldade é tanta que o Tribunal ainda não tem indicadores formulados. Pela revisão de literatura, verifica-se que o acompanhamento dos indicadores é fator fundamental no processo de monitoramento (Vaitsman, Rodrigues e Paes-Sousa, 2006; Ghisi, 2000), de forma que os Tribunais terão ainda um grande trabalho para desenvolver nessa área e aprimorarem seus sistemas de gestão.

Esses entraves à institucionalização também podem ser analisados sob a ótica do fator "tempo de implementação" da prática de gestão planejamento estratégico, conforme apontado nos achados de Santana, Colauto e Carrieri (2011). Quanto mais tempo ela for praticada, a tendência é que a prática (a estrutura) entre num estágio de total institucionalização, conforme destacado por Tolbert e Zucker (1999). Por ser recente, a institucionalização completa ainda não ocorreu na maior parte dos casos estudados.

Outro fator que corrobora o entendimento de que ainda não houve institucionalização das referidas práticas de gestão para grande parte dos Tribunais é que apenas quatro representantes concordaram totalmente com o item "o plano estratégico atualmente vem sendo monitorado e avaliado sistematicamente". Entre os quatro, três iniciaram o processo de planejamento estratégico há mais de 10 anos, indício de que o fator tempo de implementação da prática, ora mencionado, pode estar relacionado à institucionalização da mesma.

Quando abordados em relação à institucionalização da cultura de planejamento já ter ocorrido no Tribunal, na opinião de grande parte dos respondentes ainda não o foi. Apenas um respondente acredita que a cultura já foi institucionalizada. Um dos respondentes é de opinião que a mudança na cultura só ocorre se houver uma comunicação efetiva da estratégia. 
Esse tema já foi muito debatido no Grupo de Planejamento Organizacional, pois os representantes dos TC apontaram que um grande desafio é instituir a cultura de planejamento na organização e transformar a estratégia em tarefa cotidiana de todos.

Parece haver certo entrave às mudanças na cultura, pois, quando analisadas as respostas do item "existe resistência à mudança pelos servidores", grande parte dos respondentes concordaram/concordaram totalmente com a afirmação. Nesse quesito, Tolbert e Zucker (1999) apontam que, para uma total institucionalização, deve haver uma relativa baixa resistência de grupos de oposição (primeiro fator), uma vez que os atores que são afetados adversamente pelas novas estruturas podem se mobilizar de forma coletiva contra elas. Cavalluzzo e Itnner (2004) apontam que deve haver um treinamento adequado de todos os participantes do processo para que entendam e não se sintam pressionados pelo processo de mudança, mitigando, assim, riscos de falhas no processo de implementação.

O segundo fator, de acordo com Tolbert e Zucker (1999), que corrobora para a institucionalização das práticas é a promoção e apoio de um grupo de defensores (como a Alta Administração, por exemplo). Nesse sentido, quase a totalidade dos respondentes concorda/ concorda totalmente que a Alta Administração se mostra envolvida e apoia o processo de planejamento e controle. Destaca-se que o envolvimento da cúpula foi apontado como fator determinante para alcançar sucesso na implementação de um sistema de mensuração de performance por Cavalluzzo e Itnner (2004), opinião que é compartilhada pelos representantes dos TC, de acordo com registros obtidos de discussões do Grupo de Planejamento Organizacional.

Já o terceiro fator preponderante para a total institucionalização mencionado por Tolbert e Zucker (1999) é a correlação positiva com resultados desejados. Nesse quesito, o item que afirmava que "Os resultados alcançados após institucionalização do sistema de planejamento e controle foram muito melhores que os resultados apurados em programas/ações anteriores à institucionalização do sistema" obteve 52\% de concordância ou concordância total por parte dos respondentes; 39\% foram indiferentes, talvez até pelo fato de que não tiveram tempo suficiente para avaliar a melhoria nos resultados, e apenas $9 \%$ discordaram ou discordaram totalmente. Oportuno destacar que aqueles que estão à frente do processo de gestão (aqueles que têm a missão de implementar a mudança) irão defender o fato de que houve melhoria nos resultados, mesmo que essa melhoria não seja mensurada por indicadores de desempenho ou publicada aos diversos stakeholders. Tolbert e Zucker (1999) apontam que uma relação positiva fraca entre uma estrutura e os resultados desejáveis pode ser suficiente para afetar a difusão e a manutenção das estruturas.

Assim, considerando os três fatores destacados por Tolbert e Zucker (1999) para haver total institucionalização do processo, verifica-se que, apesar de haver indícios de resistência à mudança por parte dos servidores dessas organizações, os outros dois fatores parecem estar presentes para grande parte das organizações (apoio da Alta Administração — 14 TC apontaram - e melhoria dos resultados alcançados — 12 TC apontaram), segundo a percepção dos servidores das unidades de Planejamento dos Tribunais da amostra. 
Ainda em relação ao fato de que $48 \%$ dos respondentes foram indiferentes ou discordam de que "Os resultados alcançados após institucionalização ${ }^{1}$ do sistema de planejamento e controle foram muito melhores que os resultados apurados em programas/ações anteriores à institucionalização do sistema", remete-se ao ponto destacado por Meyer e Rowan (1977) de que as organizações incorporam práticas e procedimentos que prevalecem na sociedade como forma de aumentar sua legitimidade, independentemente da eficácia imediata de tais práticas e procedimentos adquiridos.

Pela análise dos resultados encontrados, verifica-se que ainda não pôde ser encontrado um padrão único de procedimentos do ciclo de planejamento estratégico que sejam adotados por todos os TC, ainda que a maioria deles tenha informado que utilizou a metodologia do TCU como referência. Existem Tribunais que adotam diferenciados modelos de desdobramento do plano estratégico e diferenciadas formas de monitoramento. Desse modo, pode-se verificar que o mimetismo está mais presente numa fase inicial de formulação estratégica do que nas fases seguintes, de implementação e de monitoramento da execução do plano, uma vez que essas são diferenciadas em cada um dos Tribunais.

Cabe destacar também que, por ser uma prática incipiente para a maioria das organizações estudadas, várias delas ainda estão experimentando alguns procedimentos até poderem escolher o mais adequado para a organização. Desse modo, aquilo que foi colocado em prática em um determinado período pode ser substituído no período seguinte por outra prática para se verificar se melhor atingem os objetivos delineados.

Entretanto, entre aqueles Tribunais que informaram se embasar na metodologia utilizada pelo TCE-RN, podem-se identificar algumas semelhanças em um grupo composto por quatro Tribunais, a saber: (i) todos implementaram o planejamento estratégico mais recentemente (quatro anos no máximo); (ii) todos concordam que o Promoex foi um fator impulsionador para implantação de um sistema de planejamento e controle; (iii) não contrataram consultoria externa para auxiliar na elaboração do plano estratégico (com exceção de $\mathrm{um}$ ), depreendendo-se que os demais usaram da expertise do TCE-RN; (iv) discordam que o plano estratégico vem sendo monitorado sistematicamente (com exceção de um que opinou ser indiferente) e reuniões de avaliação atualmente não são realizadas no processo de monitoramento.

Desse modo, verifica-se que existe um grupo de quatro Tribunais que ainda estão no início do processo, uma vez que estão implementando o primeiro ciclo de planejamento, não tendo conseguido ainda definir alguns procedimentos do sistema de monitoramento. Considerando as fases do processo de institucionalização propostas por Tolbert e Zucker (1999), esses Tribunais ainda não teriam iniciado o processo de institucionalização do planejamento estratégico na organização.

\footnotetext{
${ }^{1}$ Os questionários foram aplicados de forma presencial para que eventuais dúvidas de entendimento pudessem ser esclarecidas. Os respondentes entenderam o termo como adoção do processo de forma efetiva.
} 
Por outro lado, pode se verificar a existência de um grupo composto por três Tribunais que apresentam, em seus procedimentos, os fatores determinantes para alcançar sucesso na implementação de um sistema de monitoramento, segundo Cavalluzzo e Ittner (2004). Esses fatores são: (i) um bom sistema de informações para subsidiar o monitoramento: todos informaram que é utilizado efetivamente um sistema informatizado para monitoramento do plano estratégico; (ii) comprometimento da alta administração: todos concordaram totalmente que a alta administração se mostra envolvida e apoia o processo de planejamento e controle; (iii) treinamento adequado de todos os participantes do processo para que entendam e aceitem a mudança implementada: todos concordam que a maioria dos servidores consegue relacionar o trabalho desenvolvido com o alcance dos resultados do plano.

Além desses fatores, esse grupo também apresenta as seguintes características em comum: (i) o planejamento é um processo implementado há mais de 12 anos para dois dos TC; (ii) o plano estratégico é revisado anualmente; (iii) todos usam a metodologia BSC (um deles usa BSC com GPD); (iv) na elaboração do plano estratégico foram ouvidas sugestões dos diversos setores da instituição; (v) os prazos e metas vêm sendo monitorados (para todos) e os indicadores qualitativos e financeiros, ações e projetos apenas para dois deles; (vi) a periodicidade do monitoramento é mensal no mínimo; (vii) são realizadas reuniões de avaliação de resultados com todo o grupo de responsáveis; (viii) todos participam de Programas de Avaliação continuada/externa; (ix) todos concordam totalmente que o plano estratégico estava sendo monitorado e avaliado sistematicamente; e (x) os procedimentos do sistema de planejamento de todos eles estão normatizados e publicados.

Esses três Tribunais já conseguiram avançar no estágio de institucionalização do planejamento estratégico, segundo as fases descritas por Tolbert e Zucker (1999).

O fato de não ter sido encontrado um único padrão seguido pelos Tribunais pode estar relacionado à questão de serem instituições diferenciadas e ser difícil a comparação entre elas, conforme opinião dos respondentes da pesquisa. Apesar de a pesquisa não ter conseguido identificar um padrão de sistema de monitoramento adotado pelos Tribunais de forma geral, cabe destacar que parece existir uma congruência em relação à adoção da ferramenta planejamento estratégico, principalmente quando se verifica que os representantes das unidades de Planejamento dos Tribunais se encontram para discutir questões ligadas à metodologia de Planejamento em reuniões periódicas do Grupo de Planejamento Organizacional/Promoex (Silva, Martins e Ckagnazaroff, 2013). Um dos assuntos bastante discutidos pelo grupo nos anos de 2011 e 2012 foi a implementação do sistema informatizado de monitoramento da execução do plano estratégico, ferramenta que poderá auxiliar muito no processo de monitoramento, segundo expectativa dos representantes dos Tribunais (Silva e Mário, 2012) e também conforme verificado na literatura, já que um sistema de informações pode conferir maior eficiência e confiabilidade ao processo.

Após descrição do processo de formulação e monitoramento do planejamento estratégico, será apresentado o resultado da consulta ao conteúdo dos planos estratégicos desses Tribunais, a partir do qual será possível observar questões relativas à abrangência de elementos que compõem o planejamento estratégico em cada órgão da amostra analisada. 


\section{Considerações finais}

O objetivo deste trabalho foi descrever o processo de planejamento estratégico e monitoramento da execução do planejamento estratégico pelos Tribunais de Contas brasileiros. Para tanto, utilizou-se de pesquisa documental nos planos estratégicos dos Tribunais, assim como uma survey aplicada aos representantes das unidades de Planejamento no mês de novembro de 2012.

O histórico da implementação da ferramenta planejamento estratégico no âmbito dos Tribunais de Contas deve ser analisado, de maneira geral, sob três fases: uma antecedente ao Programa Promoex (antes de 2006); uma durante a duração do referido Programa (2006 a maio de 2013); e outra pós-Promoex. Essas fases se diferenciam, pois o Programa foi um marco para a modernização das práticas de gestão adotadas pelos Tribunais. Uma das metas do Promoex era que todos os Tribunais tivessem implementado o planejamento estratégico, ferramenta que é objeto de estudo deste trabalho.

Como se tratava de um procedimento novo e desconhecido, não havendo expertise no corpo técnico dessas organizações, a maioria dos Tribunais optou por contratar uma empresa de consultoria ou contar com apoio de outros Tribunais mais experientes no assunto, para iniciar os trabalhos da formulação estratégica. Como os respondentes informaram utilizar como referência as metodologias praticadas em outras instituições (sendo o TCU citado por grande parte deles), algumas ferramentas são comuns aos Tribunais, como a adoção do Balanced Scorecard, que é predominante na amostra estudada. Nesse ponto, aspectos do isomorfismo (Teoria Institucional) foram tratados ao longo da apresentação dos resultados.

Cabe destacar que, a despeito da predominância da ferramenta gerencial BSC nos Tribunais, não foi encontrado um padrão em relação aos procedimentos adotados por essas organizações em relação ao monitoramento da execução do plano estratégico. Existe variação em relação: à forma de desdobramento do plano de longo prazo em planos de menor duração; aos quesitos que vêm sendo monitorados (indicadores, metas, projetos, prazos, ações); à periodicidade do monitoramento; à realização de reuniões para monitoramento dos resultados (quem participa e com qual periodicidade), entre outros. Entretanto, parece haver um esforço por parte dos Tribunais para que possa haver um alinhamento de entendimentos acerca do planejamento estratégico, fato que pode ser observado pelo relato das reuniões periódicas realizadas pelo Grupo de Planejamento Organizacional/Promoex.

Conclui-se que o processo de monitoramento da execução do planejamento estratégico nos Tribunais, de forma geral, ainda está em fase de amadurecimento e nem todas as "melhores práticas" estão sendo executadas por todas essas instituições. Por mais que algumas poucas já tenham despontado, algumas outras ainda estão buscando meios de implementar os procedimentos de monitoramento, seja por meio de um software específico para tanto, seja por meio de contratação de consultoria ou de visita técnica em outras instituições para auxiliar a instituir a rotina. Considerando as fases do processo de institucionalização propostas por Tolbert e Zucker (1999), foram constatados indícios de que alguns Tribunais ainda não concluíram nem a primeira fase, habitualização, ou seja, ainda não iniciaram, de fato, a 
institucionalização da prática de planejamento estratégico. Três Tribunais, ao contrário, já se encontram numa fase de sedimentação.

Cabe destacar que os Tribunais estão passando por um processo de transformação ao instituírem a gestão com foco em resultados, definindo metas, pagando remuneração variável atrelada a indicadores (poucas delas), revisando processos de trabalho, ações que eram impensáveis na administração pública há tempos. Entretanto, para que esse processo de planejamento estratégico tenha sucesso, algumas barreiras devem ser superadas por essas instituições, como: instituir e efetuar a medição tempestiva de indicadores de desempenho que realmente reflitam o resultado organizacional; conseguir obter total apoio da alta administração, mitigando riscos de descontinuidade na execução do PE toda vez em que houver mudança na gestão; envolver os servidores para que eles se sintam parte do processo e se esforcem para alcançar as metas (o que poderia ser corroborado com um sistema de incentivos), entre outros pontos destacados neste trabalho.

Esta pesquisa não conseguiu coletar evidências suficientes para se chegar a uma conclusão sobre as causas da não institucionalização do processo de planejamento e monitoramento da execução do plano estratégico nas organizações estudadas. Sugere-se, então, que sejam realizados estudos de casos múltiplos, estratégia de pesquisa que analisa, em profundidade, um fenômeno ou processo (Yin, 2005). Por meio do estudo de caso, pode ser pesquisado, também, o impacto da troca de gestão a cada dois anos, e também pode ser diagnosticado se houve evolução nos resultados após implementação do planejamento estratégico.

\section{Referências}

BECHELAINE, Cinthia H. O. et al. A influência dos processos de institucionalização na utilização dos resultados de avaliações de políticas públicas: o caso mineiro das avaliações executivas de projetos. Revista Contabilidade, Gestão e Governança, Brasília, v. 16, n. 1, p. 82-97, 2013.

BERRY, Andrew J. et al. Emerging themes in management control: a review of recent literature. The British Accounting Review, v. 41, n. 1, p. 2-20, 2009.

BORGES, Thiago B. Utilização da informação gerencial no setor público: perspectiva diante das novas normas de contabilidade do setor público. Dissertação (mestrado em ciências contábeis) — Centro de Pós-Graduação e Pesquisas em Contabilidade e Controladoria, Universidade Federal de Minas Gerais, Belo Horizonte, 2012.

BRASIL. Constituição (1988). Constituição da República Federativa do Brasil. Brasília, Senado Federal, 5 out. 1988. Disponível em: <www.senado.gov.br/sf/legislacao/const/> . Acesso em: 9 out. 2012.

BRASIL. Ministério do Planejamento, Orçamento e Gestão. Promoex. Relatório de progresso Promoex — 1o semestre de 2012. Disponível em: <www.planejamento.gov.br/secretaria.asp?cat=487\&$\mathrm{sec}=18>$. Acesso em: 18 abr. 2013.

BRESSER-PEREIRA, Luiz C.; GRAU, Nuria C. (Coord.). Responsabilização na administração pública. São Paulo: Clad; Fundap, 2006. 
BRYSON, John M. A strategic planning process for public and non-profit organizations long range planning. Long Range Planning, v. 21, n. 1, p. 73-81, 1988.

CATELLI, Armando (Coord.). Controladoria: uma abordagem da gestão econômica - Gecon. São Paulo: Atlas, 2001.

CAVALLUZZO, Ken S.; ITTNER, Christopher D. Implementing performance measurement innovations: evidence from government. Accounting, Organizations and Society, v. 29, n. 3-4, p. 243-267, 2004.

CORRÊA, Hamilton L.; HOURNEAUX JUNIOR, Flávio. Sistemas de mensuração e avaliação de desempenho organizacional: estudo de casos no setor químico no Brasil. Revista Contabilidade \& Finanças, São Paulo, v. 19, n. 48, p. 50-64, set./dez. 2008.

CRUZ, Cássia V. O. A.; MATIAS, Márcia A.; FREZATTI, Fábio. Considerações acerca do uso do Balanced Scorecard no processo de implementação e reformulação das estratégias organizacionais. Revista de Estudos Contábeis, Londrina, v. 1, n. 1, p. 3-23, jul./dez. 2010.

DIAS FILHO, José M.; MACHADO, Luiz H. B. Abordagens da pesquisa em contabilidade. In: IUDÍCIBUS, Sérgio; LOPES, Alexsandro. B. Teoria avançada da contabilidade. São Paulo: Atlas, 2004.

DIMAGGIO, Paul J.; POWELL, Walter W. The iron cage revisited: institutional isomorphism and collective rationality in organizational fields. American Sociological Review, v. 48, n. 2, p. 147-169, 1983.

GHISI, Adhemar P. Desempenho das entidades fiscalizadoras superiores e indicadores de rendimento. Revista do TCU, Brasília, v. 31, n. 86, p. 327-337, out./dez. 2000.

GIACOBBO, Mauro. O desafio da implementação do planejamento estratégico nas organizações públicas. Revista do TCU, Brasília, v. 28, n. 74, p. 73-107, out./dez. 1997.

GUARRIDO FILHO, Edson R. A construção da teoria institucional nos estudos organizacionais no Brasil: o período 1993-2007. Tese (doutorado em administração) - Centro de Pesquisa e Pós-Graduação e Pesquisa em Administração, Universidade Federal do Paraná, Curitiba, 2008.

GUIMARÃES, Tadeu B.; PORDEUS, Iran A.; CAMPOS, Éder S. A. (Org.). Estado para resultados: avanços no monitoramento e avaliação da gestão pública em Minas Gerais. Belo Horizonte: Editora UFMG, 2010.

HOOD, Christopher. The "New Public Management" in the 1980s: variations on a theme. Accounting, Organization and Society, Oxford, v. 20, n. 2-3, p. 93-109, 1995.

INSTITUTO RUI BARBOSA. Pesquisa sobre Tribunais de Contas do Brasil. Percepção do Corpo Deliberativo. Disponível em: <www.tce.ma.gov.br/publicacoes/documento/arquivos/Pesquisa\%20 Atualizacao\%20de\%20Diagnostico.pdf>. Acesso em: 10 abr. 2014.

INTOSAI. International Organization of Supreme Audit Institutions. Supreme audit institutions performance measurement framework. Concept note. Disponível em: <www.idi.no/artikkel.aspx?MId1=102\&AId=704> . Acesso em: 30 set. 2013. 
KAPLAN, Robert; NORTON, David. The balanced scorecard: measures that drive performance. Harvard Business Review, v. 1, p. 71-79, jan./fev. 1992.

LEWIN, Kurt. Problemas de dinâmica de grupo. São Paulo: Cultrix, 1948.

MACHADO-DA-SILVA, Clóvis L.; VIZEU, Fábio. Análise institucional de práticas formais de estratégia. Revista de Administração de Empresas, São Paulo, v. 47, n. 4, p. 89-100, out./dez. 2007.

MARTINS, Gilberto A. Sobre confiabilidade e validade. Revista Brasileira de Gestão e Negócios, São Paulo, v. 8, n. 20, p. 1-12, jan./abr. 2006.

MEIRELLES, Anthero de M. A formação de estratégia no sistema bancário brasileiro: modelo teórico e evidências empíricas. Tese (doutorado em administração) — Centro de Pós-Graduação e Pesquisa em Administração, Universidade Federal de Minas Gerais, Belo Horizonte, 2003.

MEYER, John; ROWAN, Brian. Institutionalized organizations: formal structure as myth and ceremony. American Journal of Sociology, v. 83, n. 2, p. 340-363, set. 1977.

MINTZBERG, Henry. Criando organizações eficazes. 2. ed. São Paulo: Atlas, 2006. cap. 4.

NATIONAL AUDIT OFFICE. Our strategy. Disponível em: <www.nao.org.uk/about-us/what-we-do/ our-strategy/>. Acesso em: 10 abr. 2014.

PEREIRA, Luiz A. C. et al. Reações de afeto no processo decisório gerencial das organizações: uma abordagem a partir da Prospective Theory. Revista Contabilidade Vista \& Revista, Belo Horizonte, v. 21, n. 1, p. 131-155, jan./mar. 2010.

PEREIRA, Sérgio C. de S. O planejamento estratégico em organizações públicas: um estudo de caso das organizações militares prestadoras de serviço. In: CONGRESO INTERNACIONAL DEL CLAD SOBRE LA REFORMA DEL ESTADO Y DE LA ADMINISTRACIÓN PÚBLICA, XI, 2006, Ciudad de Guatemala. Anais eletrônicos... Disponível em: <www.docstoc.com/docs/20547112/O-planejamento-estrat\%C3\%A9gico-em-organiza\%C3\%A7\%C3\%B5es-p\%C3\%BAblicas-um-estudo-de >. Acesso em: 24 fev. 2013.

POISTER, Theodore. H. The future of strategic planning in the public sector: linking strategic management and performance. Public Administration Review, v. 70, n. esp., p. 246-254, dez. 2010.

REIS, Luciano G. A influência do discurso no processo de mudança da contabilidade gerencial: um estudo de caso sob o enfoque da Teoria Institucional. Tese (doutorado em ciências contábeis) Programa de Pós-graduação em Ciências Contábeis, Departamento de Ciências Contábeis, Faculdade de Economia, Administração e Contabilidade, Universidade de São Paulo, São Paulo, 2008.

RIBEIRO, João A.; SCAPENS, Robert W. Institutional theories in management accounting change: contributions, issues and paths for development. Qualitative Research in Accounting \& Management, v. 3, n. 3, p. 94-111, 2006.

RIBEIRO, Renato J. B. O problema central do controle da administração pública pode ser resumido ao debate sobre modelos? Revista do Tribunal de Contas da União, v. 33, n. 93, p. 55-73, jul./set. 2002. 
ROBBINS, Stephen P. Comportamento organizacional. 8. ed. Rio de Janeiro: LTC, 1999.

RODRIGES NETO, Antônio J. M. (Org.). A era do cidadão. A experiência do Tribunal de Contas de Mato Grosso. Cuiabá: Entrelinhas, 2009.

SANTANA, Gislaine P. S.; COLAUTO, Romualdo D.; CARRIERI, Alexandre P. Institucionalização de instrumentos gerenciais: o caso de uma organização do setor elétrico. Revista Iberoamericana de Contabilidad de Gestión, Espanha, v. 9, n. 18, p. 1-18, jul./dez. 2011.

SCOTT, W. Richard. The Adolescence of Institutional Theory. Administrative Science Quarterly, v. 32, n. 4, p. 493-511, 1987.

SELZNICK, Philip. Liderança na administração: uma interpretação sociológica. Rio de Janeiro: Fundação Getulio Vargas, 1972.

SILVA, Flávia A.; GONÇALVES, Carlos A. O processo de formulação e implementação do planejamento estratégico em instituições públicas. Revista de Administração da UFSM, v. 4, n. 3, p. 458-476, set./dez. 2011.

SILVA, Flávia A.; MÁRIO, Poueri C. Monitoramento e avaliação nas instituições públicas: um estudo nos Tribunais de Contas no Brasil. In: CONGRESSO NACIONAL DE ADMINISTRAÇÃO E CIÊNCIAS CONTÁBEIS — ADCONT, 3., 2012, Rio de Janeiro. Anais... Rio de Janeiro: Faculdade de Administração e Ciências Contábeis/UFRJ, 9-11 out. 2012.

SILVA, Flávia A.; MARTINS, Túlio C. P. M.; CKAGNAZAROFF, Ivan B. Redes organizacionais no contexto da governança pública: a experiência dos Tribunais de Contas do Brasil. Revista do Serviço Público, v. 64, n. 2, p. 249-272, abr./jun. 2013.

SIMONS, Robert; DÁVILA, Antonio; KAPLAN, Robert S. Performance Measurement and control systems for implementing strategy. Nova Jersey: Prentice Hall, 2000. cap. 10 e 11.

TALBOT, Collin; DAUNTON, Lyn; MORGAN, Colin. A mensuração do desempenho de ministérios e agências de governo: evoluções internacionais. Revista do Serviço Público, Brasília, v. 52, n. 3, p. 5-51, jul./set. 2001.

TOLBERT, Pamela S.; ZUCKER, Lynne G. A institucionalização da teoria institucional. In: CLEGG, Stewart; HARDY, Cynthia et al. (Org.). Handbook de estudos organizacionais, modelos de análise e novas questões em estudos organizacionais. São Paulo: Atlas, 1999. v. 1, p. 194-217.

TRIVIÑOS, Augusto N. S. Introdução à pesquisa em ciências sociais: a pesquisa qualitativa em educação. São Paulo: Atlas, 2007.

U. S. GOVERNMENT AUDIT OFFICE. Performance measures. Disponível em: <www.gao.gov/about/ perfmeasures.html>. Acesso em: 10 abr. 2014.

VAITSMAN, Jeni; RODRIGUES, Roberto W. S.; PAES-SOUSA, Rômulo. O sistema de avaliação $e$ monitoramento das políticas e programas sociais: a experiência do Ministério do Desenvolvimento Social e Combate à Fome do Brasil. Brasília: Unesco, 2006. Policy Papers, 17. 
WEBER, Max. Economia e sociedade: fundamentos da sociologia compreensiva. Tradução de Regis Barbosa e Karen Elsabe Barbosa. 3. ed. Brasília: Ed. da UnB, 1994.

YIN, Robert K. Estudo de caso: planejamento e métodos. 3. ed. Porto Alegre: Bookman, 2005.

Flávia de Araújo e Silva é professora do Departamento de Ciências Contábeis da Universidade Federal de Minas Gerais (UFMG) e mestre em Ciências Contábeis pela UFMG. E-mail: flavia.admin@gmail.com. Poueri do Carmo Mário é professor Associado da Universidade Federal de Minas Gerais (UFMG) e professor adjunto do MPA-UNA. Doutor em ciências contábeis pela USP. E-mail: poueri@gmail.com. 